Original Article

Artigo Original

Maribel Hilasaca-Mamani ${ }^{1}$

Taís de Souza Barbosa ${ }^{1}$

Claudia Fegadolli2

Paula Midori Castelo²

Keywords

Mastication

Tests Validity

Dental Caries

Adolescent

Malocclusion
Correspondence address:

Paula Midori Castelo

Departamento de Ciências Biológicas, Universidade Federal de São Paulo

Rua São Nicolau, 210, $1^{\circ}$ andar,

Diadema (SP), Brazil, CEP: 09913-030.

E-mail: pcastelo@yahoo.com

\section{Validity and reliability of the quality of masticatory function questionnaire applied in Brazilian adolescents}

\begin{abstract}
Purpose: proper chewing and swallowing functions have great importance in general health, since it potentially affects food's digestion and the subject's nutritional status. The aim was to assess the validity and reliability of the self-applied Quality of Masticatory Function Questionnaire (QMFQ) in a convenience (non-referred) sample of Brazilian adolescents divided into three groups: control $(\mathrm{n}=57)$, dental caries $(\mathrm{n}=51)$ and malocclusion $(\mathrm{n}=54)$. Methods: caries and malocclusion were evaluated using DMF-S index (number of decayed, missing and filled primary and permanent surfaces) and Index of Orthodontic Treatment Need, respectively. The QMFQ comprises 26 items regarding frequency and intensity of chewing problems with five domains: Food-Mastication, Habits, Meat, Fruits and Vegetables. Data were submitted to descriptive statistics, Kolmogorov-Smirnov and Chi-square tests. Psychometric evaluation included measures of reliability (internal consistency - Cronbach's alpha and matrix of correlation) and discriminant validity (Kruskal-Wallis/Dunn post-test). Results: the instrument showed satisfactory internal consistency, with significant positive correlations between the domains scores except between Habits and Vegetables. Total scale Cronbach's alpha coefficient was 0.87 and the coefficient did not increase significantly with the removal of each domain. Significant differences were found between controls and caries group in Food-Mastication, Meat and Fruits scores. Caries group also showed higher median values in Food-Mastication and Fruits than the malocclusion group. Conclusion: the Quality of Masticatory Function Questionnaire showed acceptable properties regarding internal consistency, reliability, and discriminant validity in evaluating the impact of caries on the perception of the masticatory function quality of Brazilian adolescents.
\end{abstract}

\section{INTRODUCTION}

The health status of the teeth, tongue, cheeks, lips, muscles and saliva are essential to properly perform important oral functions such as talking, laughing, smiling, yawning, swallowing and chewing ${ }^{(1)}$. Proper chewing and swallowing functions have great importance since they affect food's digestion and have potential influence on the subject's nutritional status $^{(2)}$ and on individual's quality of life ${ }^{(3)}$. In this context, when evaluating masticatory efficiency, maximum values are obtained by individuals with complete healthy dentition, while lower values are obtained by patients with teeth losses ${ }^{(4,5)}$.

Food fragmentation depends on the number of teeth present, number of occlusal units, and tooth surface area. This explains the fact that subjects with teeth compromised by periodontal diseases and/or dental caries swallow large particles or spend more time chewing ${ }^{(6,7)}$. According to previous studies, subjects with malocclusions may have fewer occlusal contacts or smaller contact areas, thus showing poor masticatory performance ${ }^{(8)}$.

Study carried out at Departamento de Odontologia Infantil, Faculdade de Odontologia de Piracicaba, Universidade de Campinas - UNICAMP - Piracicaba (SP), Brazil.

${ }^{1}$ Faculdade de Odontologia de Piracicaba, Universidade de Campinas - UNICAMP - Piracicaba (SP), Brazil.

${ }^{2}$ Universidade Federal de São Paulo - UNIFESP - Diadema (SP), Brazil.

Financial support: Fundação de Amparo à Pesquisa do Estado de São Paulo - FAPESP, grant n. 2012/04492-2 and 2014/24804-4.

Conflict of interests: nothing to declare.

Received: March 13, 2015 
Masticatory function can be subjectively evaluated, by means of questionnaires or visual analogic scales, or objectively, by myofunctional evaluations ${ }^{(9)}$, masticatory performance ${ }^{(3,5,8)}$ and/or efficiency measures, which verify the subject's ability to reduce food to small particles. Chewing ability is the subjective assessment of an individual's masticatory function. Previous studies failed to reveal a significant relationship between masticatory ability and performance/efficiency, probably because the subjective evaluation can capture the impact of oral health on daily lives of these subjects ${ }^{(10)}$. Also, the subjective assessment may include other aspects of masticatory function, such as the ability to adapt to daily activities and the psychological factors, which may not be obtained by objective measures ${ }^{(1)}$. To our knowledge, there are very few instruments aiming to evaluate chewing ability, and no specific validated instrument was found in the literature.

A measuring instrument should be valid, reliable, and also present important features as: must not be too long, be easily understood and must be sensitive to changes in the attribute that it is supposed to measure. Adapting pre-existing instruments is preferable over developing a new one because creating a new test can be costly and time-consuming; moreover, the use of the same instrument provides a common measurement for the investigation within different cultural contexts, countries and populations ${ }^{(11)}$. After translation and cross-cultural adaptation, the instrument must be tested for its psychometric properties since the linguistic and cultural context in which a measure is used may influence its validity ${ }^{(12)}$. When an instrument is submitted to a validation procedure, the purpose of the instrument is actually being validated ${ }^{(13)}$. The reliability should also be ensured, in terms of internal consistency among the items and domains, as well as the reproducibility.

When measuring the chewing ability regarding diet, it is important to understand of how people prepare and choose their foods. Thus, the present study aimed to evaluate the validity and reliability of the Quality of Masticatory Function Questionnaire applied in Brazilian adolescents with different oral health status.

\section{METHODS}

The Portuguese version of the Quality of Masticatory Function Questionnaire (QMFQ) was developed previously, after translation and cross-cultural adaptation of the Questionnaire $D^{\prime}$ 'Alimentation ${ }^{(14)}$; this instrument was originally developed for French speaking adults who wore partial/complete dentures living in Montreal (Quebec) and the English version has already been presented ${ }^{(15)}$. It is important to point out that the authors of the Questionnaire D'Alimentation were contacted prior the validation process.

This study was approved by the Research Ethics Committee of the Piracicaba Dental School, University of Campinas, protocol number 108/2012. The Informed Consent was signed by the patient's responsible.

\section{Sample}

A convenience sample was selected among adolescents from public schools of Piracicaba, SP (Brazil); about 500 subjects aged 11-14 years were evaluated for inclusion/exclusion criteria and, from those, 162 were selected and divided into three groups: control group $(\mathrm{n}=57)$, caries group $(\mathrm{n}=51)$ and malocclusion group $(\mathrm{n}=54)$ (Table 1$)$.

Sample size was calculated according to previous studies found in the literature; impact of dental caries on children's self-perception of mastication was evaluated in 695 Brazilian schoolchildren (aged 12 years) ${ }^{(16)}$. Taking into account $\mathrm{X} 2=8.870,80 \%$ power and an alpha level of 0.05 , we determined the need of 89 subjects with and without caries experience to perform the evaluations.

Sample size calculation for malocclusion group was based in a previous study ${ }^{(17)}$ which also used the instrument OHIP-14 in the evaluation of young adults with and without orthodontic treatment needs; the specific item "Found it uncomfortable to eat food" was associated to subjects with orthodontic treatment needs $(X 2=9.114$ and $p=.0105)$. Considering $80 \%$ power and alpha $=0.05$, a total of 106 adolescents would be needed to compare individuals with and without orthodontic treatment needs.

The inclusion criterion was full permanent dentition (with the exception of third molars). The exclusion criteria evaluated during the interview were systemic disturbance which could compromise the masticatory system, neurological disorders, cerebral palsy, and chronic diseases (diabetes, hypertension), among others; presence of parafunctional habits (sucking habits, nail biting, bruxism); tooth or temporomandibular joints pain; use of medicines which interfere in the central nervous system (anxiolytics, antidepressants, anticonvulsants), i.e., central nervous system depressants; inappropriate behavior and/or refusal.

In the interview, another simple evaluation concerning masticatory function and satisfaction was also conducted for further comparison with the Quality of Masticatory Function Questionnaire scores, using four questions with qualitative answers (yes/no):

Table 1. Sample characteristics according to age, gender, caries experience and orthodontic treatment needs

\begin{tabular}{|c|c|c|c|c|c|}
\hline & & & Age & DMFS/dmf-s & IOTN \\
\hline Group & $\mathrm{n}$ & Gender & $\begin{array}{c}\text { Mean } \\
\text { (SD) }\end{array}$ & $\begin{array}{c}\text { Mean } \\
\text { (SD) }\end{array}$ & $\begin{array}{c}\text { Mean } \\
\text { (SD) }\end{array}$ \\
\hline Control & 57 & $30+27 \lesssim$ & $12.1(0.8)$ & $0.0(0.0)$ & $1.0(1.0)$ \\
\hline Caries & 51 & $33+18 \lambda$ & $12.0(0.8)$ & $4.8(2.1)$ & $1.7(0.5)$ \\
\hline Malocclusion & 54 & $29+25 \lambda$ & $12.0(0.8)$ & $0.0(0.0)$ & $4.2(0.4)$ \\
\hline
\end{tabular}

DMFS/dmf-s, number of decayed, lost and filled primary or permanent surfaces; IOTN, Index of Orthodontic Treatment Need 
1. Was your choice of food limited because of your teeth?

2. Do you have chewing difficulty because of your teeth?

3. Do you drink water to help chew?

4. Do you have chewing difficulty on the right or left side?

\section{Clinical oral and dental examinations}

The clinical oral and dental examinations were performed at schools, using a mirror with an artificial LED light and probe, following biofilm control. Caries experience was evaluated by determining the number of decayed, missing and filled primary and permanent surfaces (DMFS and dmf-s, respectively). Molars and premolars were considered having 5 surfaces, front teeth 4 surfaces. The intraexaminer reproducibility was previously evaluated (Kappa coefficient $=0.83$; $n=16$ ).

Occlusal evaluation was performed using the Index of Orthodontic Treatment Needs (IOTN) - Dental Health Component (DHC), which is based on the contribution of various occlusal characteristics to the orthodontic treatment needs. The DHC measurements were obtained using a probe, and individuals were classified on a scale of five degrees in ascending order of orthodontic treatment needs: no need for treatment, little need, moderate need/borderline, great need and very great need ${ }^{(18)}$. The three study groups were then consisted of subjects presenting the following characteristics:

- Control group: $\mathrm{DMFS}=0$ and $\mathrm{IOTN}=1$;

- Caries group: DMFS $\geq 3$ and IOTN=1 or 2 ;

- Malocclusion group: $\mathrm{DMFS}=0$ and $\mathrm{IOTN}=4$ or 5 .

\section{Quality of masticatory function questionnaire (QMFQ)}

This self-applied questionnaire consists of 26 questions specifically related to the frequency of and difficulty on chewing different types of foods during the two weeks before the evaluation. The translation and cross-cultural adaptation of the original instrument (Questionnaire D'Alimentation) were performed previously by Hilasaca-Mamani et al. ${ }^{(14)}$ following the guidelines proposed by Guillemin et al. ${ }^{(11)}$. The English version was also previously showed ${ }^{(15)}$, although it has not been validated.

The domains Food-Mastication, Habits, Meats, Fruits and Vegetables have 5 Likert-response options ranging from "always" to "never" or "a lot" to "no difficulty". In addition, the domains Meats, Fruits and Vegetables also present an alternative to be checked (not applicable - N/A) if the subject does not usually eat these foods. A high score indicates more negative impacts on quality of masticatory function.

\section{Statistical analysis}

Data were statistically evaluated using the BioEstat 5.3 (Mamirauá, Belém, PA, Brazil), SPSS 18.0 (SPSS Inc., Chicago, EUA), and SigmaPlot 11.0 (Systat Software Inc., San Jose, California, USA) statistical software packages considering $\alpha=0.05$. The descriptive statistics consisted of means, standard deviation, median, percentages and Chi-square test. The Kolmogorov-Smirnov test of normality was used to verify distribution of the variables; for those that presented deviation from normal distribution, non-parametric tests or logarithmic transformation were used.

The scores were summed for each domain considering the response options. Missing-data imputation was performed when responses were left blank or the alternative response (N/A, not applicable) was checked, using the average of the domain's scores obtained for each subject).

Psychometric evaluation included measures of reliability (internal consistency) and discriminant validity. Internal consistency was assessed by means of a correlation matrix between the domains and Cronbach's Alpha coefficient for total scale and with the removal of each domain, in order to verify the instrument's homogeneity. Ceiling and floor effects were also determined.

The discriminant validity was tested using Kruskal-Wallis test and Dunn's post-test, allowing discrimination between groups with different characteristics, i.e., controls, caries experience, and malocclusion. Also, the Spearman correlation test was used to determine the correlation between the scores of IOTN and the scores obtained in each domain of QMFQ.

Chi-square test was used to determine the proportion of individuals who reported chewing difficulty in each group evaluated by means of four simple qualitative questions.

\section{RESULTS}

Table 1 shows the characteristics of the sample in accordance to age, gender, caries experience and orthodontic treatment needs. The proportion of girls and boys among groups did not vary significantly $(\mathrm{p}=.384)$.

QMFQ showed satisfactory internal consistency, since there was a significant positive correlation between the scores of the five domains ( $p=.0001$; Spearman correlation test), except between the domains Habits and Vegetables (Table 2). Of the

Table 2. Quality of Masticatory Function Questionnaire - internal consistency: correlation matrix between the domains

\begin{tabular}{cccccc}
\hline$r(p-v a l u e)$ & Food-mastication & Habits & Meat & Fruits & Vegetables \\
\hline Food-mastication & - & $0.35(0.0001)$ & $0.55(0.0001)$ & $0.57(0.0001)$ & $0.39(0.0001)$ \\
Habits & - & - & $0.49(0.0001)$ & $0.36(0.0001)$ & $0.10(0.1870)$ \\
Meat & - & - & - & $0.51(0.0001)$ & $0.32(0.0001)$ \\
Fruits & - & - & - & - & $0.44(0.0001)$ \\
Vegetables & - & - & - & - & - \\
\hline
\end{tabular}

\footnotetext{
r: Spearman correlation coefficient
} 
162 subjects included, missing values occurred in only 9 (nine) questionnaires.

When considering the entire sample, the QMFQ domains showed floor effect (index above 10\%), although ceiling effect was not observed in any domain (Table 3). The Cronbach's alpha of the total scale was 0.87 ; Cronbach's alpha with the removal of each domain separately did not increase significantly $(0.81-0.88)$.

Table 4 shows the results of the discriminant validity. There was a statistically significant difference between the scores of the control group and caries group in domains Food-Mastication, Meat and Fruits; caries group showed higher median. Caries group also showed higher median values than the malocclusion group in domains Food-Mastication $(6.0$ vs $2.0 ; \mathrm{p}<0.05)$ and Fruits (4.0 vs $2.5 ; \mathrm{p}<0.05)$.

In malocclusion group, the discriminant validity was also tested using a correlation test, although the coefficients found between scores of IOTN and each domain of QMFQ were not significant ( $\mathrm{p}$-values ranged between 0.465 and 0.991 ).

Table 5 shows the percentage of positive responses obtained in each of the four qualitative questions related to masticatory function and satisfaction. By means of statistical analysis, it was observed that the proportion of positive responses did not vary between groups.

\section{DISCUSSION}

This study aimed to evaluate the validity and reliability of QMFQ applied in Brazilian adolescents. The linguistic and cultural context in which a questionnaire will be used may influence its validity; therefore, the instrument should be translated, back-translated and cross-culturally adapted in order to ensure their equivalence ${ }^{(11,12)}$, which was made previously ${ }^{(14)}$. And every time an instrument is used in a new context or with different group of individuals, it is necessary to test its psychometric properties.

The results of this study suggest that QMFQ have good internal consistency, as significant positive correlations between the domains scores were observed; the domains should consider various aspects of the same construct, but they should not be redundant. The exception was the correlation between Habits and Vegetables domains $(\mathrm{r}=0.10$; not significant); this finding may be explained by the fact that the alternative response N/A (not applicable) was checked with great frequency in domain Vegetables, probably because this kind of food has little acceptance among adolescents.

With regard to the internal consistency, the Cronbach's alpha coefficient found showed homogeneity of the scale (0.87). According to the Scientific Advisory Committee of the Medical Outcomes Trust ${ }^{(19)}$, the minimum acceptable values for internal consistency are 0.70 for intergroup comparisons and $0.90-0.95$ for individual comparisons. The coefficient was also tested by removing each domain separately and no significant increase was observed in either the assumptions (0.81 - 0.88), indicating that there is no need to remove any of the domains.

The floor effect is observed when a percentage of the individuals scores at the lowest level of the measure (index above $10 \%$ ), which may impair the detection of change in situations of deteriorating health condition and may influence the sensitivity

Table 3. Quality of Masticatory Function Questionnaire - internal consistency: ceiling and floor effects, Cronbach's Alpha coefficient for total scale and Alpha if domain is deleted

\begin{tabular}{|c|c|c|c|c|c|c|}
\hline \multirow{2}{*}{ Domains } & \multicolumn{2}{|c|}{ Floor effect ${ }^{*}$} & \multicolumn{2}{|c|}{ Ceiling effect ${ }^{\dagger}$} & \multirow{2}{*}{$\begin{array}{l}\text { Cronbach's } \\
\text { Alpha }\end{array}$} & \multirow{2}{*}{$\begin{array}{l}\text { Domain- } \\
\text { deleted Alpha }\end{array}$} \\
\hline & $\mathrm{n}$ & $\%$ & $\mathrm{n}$ & $\%$ & & \\
\hline Food-Mastication $(0-36)^{\ddagger}$ & 37 & 22.8 & 1 & 0.6 & - & 0.81 \\
\hline Habits $(0-16)^{\ddagger}$ & 27 & 16.7 & 1 & 0.6 & - & 0.88 \\
\hline Meat $(0-20)^{\ddagger}$ & 57 & 35.2 & 3 & 1.9 & - & 0.84 \\
\hline Fruits $(0-20)^{\ddagger}$ & 50 & 30.9 & 0 & 0.0 & - & 0.84 \\
\hline Vegetables $(0-12)^{\ddagger}$ & 39 & 24.1 & 7 & 4.3 & - & 0.88 \\
\hline Scale & - & - & - & - & 0.87 & - \\
\hline
\end{tabular}

* $\%$ of children with score $=0 ; \uparrow \%$ of children with maximum score; $\ddagger$ interval of possible values

Table 4. Quality of Masticatory Function Questionnaire - discriminant validity: score comparison among groups

\begin{tabular}{|c|c|c|c|c|c|}
\hline \multirow{2}{*}{ Group } & Food-Mastication & Habits & Meat & Fruits & Vegetables \\
\hline & \multicolumn{5}{|c|}{ Median (25-75\%) } \\
\hline Control & $2.0^{A}(0.0-5.0)$ & $2.0(1.0-4.0)$ & $1.0^{\mathrm{A}}(0.0-3.0)$ & $2.0^{A}(0.0-4.0)$ & $4.0(0.0-5.0)$ \\
\hline Caries & $6.0^{\mathrm{B}}(2.0-9.0)$ & $3.0(2.0-4.5)$ & $3.0^{B}(1.0-5.5)$ & $4.0^{B}(2.0-8.0)$ & $4.0(2.0-6.0)$ \\
\hline Malocclusion & $2.0^{\mathrm{AC}}(0.3-5.0)$ & $3.0(1.0-5.0)$ & $2.0(0.0-3.8)$ & $2.5^{\mathrm{AC}}(0.0-5.0)$ & $3.5(0.5-4.0)$ \\
\hline
\end{tabular}

$\mathrm{A} \neq \mathrm{B} \neq \mathrm{C}(\mathrm{p}<0.05 ;$ Kruskal Wallis test and Dunn post-test $)$

Table 5. Percentage of positive responses obtained in each qualitative question related to masticatory function and satisfaction

\begin{tabular}{|c|c|c|c|c|c|}
\hline & Question & Control & Caries & Malocclusion & $p$-value ${ }^{\dagger}$ \\
\hline 1 & Was your choice of food limited because of your teeth? & 14.0 & 27.5 & 18.5 & 0.209 \\
\hline 2 & Do you have chewing difficulty because of your teeth? & 14.0 & 31.4 & 20.4 & 0.089 \\
\hline 3 & Do you drink water to help chew? & 24.6 & 37.3 & 33.3 & 0.343 \\
\hline 4 & Do you have chewing difficulty on the right or left side? & 22.8 & 31.4 & 18.5 & 0.294 \\
\hline
\end{tabular}

† Chi-square test 
and responsiveness of the instrument. The ceiling effect (index above $10 \%$ ) was not observed in any of the domains, while floor effect was high, and, therefore, some minimal alterations in the instrument would be proposed; according to Leão and Oliveira ${ }^{(20)}$ even instruments that had gone through a careful translation and adaptation processes are likely to require minor modifications. So, patients who presented minimal scores must be carefully assessed when it is desired to monitor the quality of mastication over time or the changes related to the effect of some treatment.

Validity refers to the degree to which a scale truly reflects the phenomenon under study or how well a test measures what it is purported to measure. When the discriminant validity was checked, the caries group reported great frequency of chewing difficulty, specifically meat and fruit, when compared with the control group. The domain Food-Mastication also showed higher scores in the caries group than the control and malocclusion groups. As children with caries experience may have higher impacts on their oral health-related quality of life (OHRQL) ${ }^{(12)}$, the lack of functional occlusal contacts in a deteriorated dental health may be relevant for their masticatory capacity, as observed previously ${ }^{(21,22)}$. The presence of tooth decay or inadequate restorations can decrease the number of occlusal contacts or generate pain, thus compromising food grinding ability and leading the individual to avoid certain foods ${ }^{(23)}$. In agreement with these results, the study by Peres et al. ${ }^{(16)}$ showed that the greater the number of decayed teeth, the greater the chances to fell dissatisfaction with chewing.

The QMFQ scores of the malocclusion group were not different from the control group, in any of the domains. Comparing with caries group, the malocclusion group showed less chewing difficulty in domains Food-Mastication and Fruits. Similarly, Foster Page et al ${ }^{(4)}$ observed that children with caries experience presented higher impact in OHRQL than those with malocclusion; according to the authors, only malocclusions with a severe degree may produce significant negative effects in orofacial functions. Also, studies have reported that the number of teeth in contact and occlusal area are more important than the presence of malocclusion per $s e^{(1,24)}$. Other authors have suggested that the presence of malocclusion in adolescents is more related to psychosocial impacts than functional disabilities ${ }^{(25,26)}$. The study of Barbosa et al. ${ }^{(12)}$ also fails to find good discriminant validity in OHRQL between children with different levels of malocclusion severity, and other studies also showed a lack of a marked difference ${ }^{(26)}$.

The four qualitative questions applied during the interview were intended to evaluate whether a simplified assessment would be able to discriminate groups with different oral characteristics, using dichotomous responses (yes/no). Similarly, previous studies used the visual analogue scale to a more general assessment, which face the questions "How well do you chew?" or "Do you experience discomfort when chewing?" the patient reminded a visual score ranging from zero to $10^{(27,28)}$, or even from 1 to $5^{(29)}$. A previous study also used a simple evaluation which questioned "Are you satisfied with chewing?"(16). The results of the present study showed no significant variation in the proportion of positive responses among the three groups (normal, caries and malocclusion), in disagreement with that found by the QMFQ, showing that a simplified evaluation is not sensitive enough and may not cover and capture the different domains within a construct.

The QMFQ proved to be valid for the study of the quality of masticatory function in subjects with and without caries experience; they were selected from public schools, i.e., non-referred sample, which improves the generalization of the results found. Moreover, the non-response rate was less than $10 \%$, which does not justify alterations or revision of the questions $^{(30)}$.

Chewing difficulty related to poor dental health and swallowing disorders may lead to alterations in food choices, such as lower consumption of fruits and vegetables, and those subjects may be at risk for nutrient deficiencies ${ }^{(2)}$. Given the cross-sectional nature of the present data, it is advisable to test the responsiveness over time or related to the effect of dental or orofacial treatments, such as restorative procedures and orofacial/myofunctional rehabilitations.

\section{CONCLUSION}

The main contribution of this study was to demonstrate the acceptable measurement properties of the Quality of Masticatory Function Questionnaire in terms of internal consistency, reliability, and discriminant validity in capturing the impact of caries experience on the quality of masticatory function perception among Brazilian adolescents.

Thus, this instrument may be useful in the evaluation of masticatory function and feeding or swallowing disorders that may affect food intake among different populations and conditions (e.g. patients presenting chewing and/or swallowing disorders, denture users, patients undergoing bariatric surgery, and others).

\section{ACKNOWLEDGEMENTS}

The authors gratefully acknowledge Professor Jocelyne Feine (School of Dentistry, McGill University, Canada) for her assistance. We also acknowledge the volunteers of the study.

\section{REFERENCES}

1. van der Bilt A. Assessment of mastication with implications for oral rehabilitation: a review. J Oral Rehabil. 2011;38(10):754-80. http://dx.doi. org/10.1111/j.1365-2842.2010.02197.x. PMid:21241351.

2. Mann T, Heuberger R, Wong $H$. The association between chewing and swallowing difficulties and nutritional status in older adults. Aust Dent J. 2013;58(2):200-6. http://dx.doi.org/10.1111/adj.12064. PMid:23713640.

3. Barbosa TS, Tureli MCM, Nobre-dos-Santos M, Puppin-Rontani RM, Gavião MB. The relationship between oral conditions, masticatory performance and oral health-related quality of life in children. Arch Oral Biol. 2013;58(9):1070-7. http://dx.doi.org/10.1016/j.archoralbio.2013.01.012. PMid:23453082.

4. Foster Page LA, Thomson WM, Jokovic A, Locker D. Validation of the child perceptions questionnaire (CPQ 11-14). J Dent Res. 2005;84(7):64952. http://dx.doi.org/10.1177/154405910508400713. PMid:15972595.

5. Borges TF, Regalo SC, Taba M Jr, Siéssere S, Mestriner W Jr, Semprini M. Changes in masticatory performance and quality of life in individuals with chronic periodontitis. J Periodontol. 2013;84(3):325-31. http://dx.doi. org/10.1902/jop.2012.120069. PMid:22548588. 
6. Hildebrandt GH, Dominguez BL, Schork MA, Loesche WJ. Functional units, chewing, swallowing, and food avoidance among the elderly. J Prosthet Dent. 1997;77(6):588-95. http://dx.doi.org/10.1016/S0022-3913(97)701008. PMid:9185051.

7. Sheiham A, Steele JG, Marcenes W, Lowe C, Finch S, Bates CJ, et al. The relationship among dental status, nutrient intake, and nutritional status in older people. J Dent Res. 2001;80(2):408-13. http://dx.doi.org/10.1177/0 0220345010800020201 . PMid:11332523.

8. Owens S, Buschang PH, Throckmorton GS, Palmer L, English JD. Masticatory performance and areas of occlusal contact and near contact in subjects with normal occlusion and malocclusion. Am J Orthod Dentofacial Orthop. 2002;121(6):602-9. http://dx.doi.org/10.1067/mod.2002.122829. PMid: 12080313.

9. Picinato-Pirola MNC, Mello-Filho FV, Trawitzki LVV. Chewing time and chewing strokes in different dentofacial deformities. J Soc Bras Fonoaudiol. 2012;24(2):130-3. http://dx.doi.org/10.1590/S2179-64912012000200007. PMid:22832679.

10. Castro RAL, Portela MC, Leão AT. Cross-cultural adaptation of quality of life indices for oral health. Cad Saude Publica. 2007;23(10):2275-84. http://dx.doi.org/10.1590/S0102-311X2007001000003. PMid:17891289.

11. Guillemin F, Bombardier C, Beaton D. Cross-cultural adaptation of healthrelated quality of life measures: literature review and proposed guidelines. J Clin Epidemiol. 1993;46(12):1417-32. http://dx.doi.org/10.1016/08954356(93)90142-N. PMid:8263569.

12. Barbosa TS, Tureli MC, Gavião MB. Validity and reliability of the Child Perceptions Questionnaires applied in Brazilian children. BMC Oral Health. 2009;9:13.

13. Perroca MG, Gaidzinski RR. Patient classification system: construction and validation of an instrument. Rev Esc Enferm USP. 1998;32(2):153-68. PMid:9823228.

14. Hilasaca-Mamani M, Barbosa TS, Feine J, Ferreira RI, Boni RC, Castelo PM. Brazilian translation and adaptation of the Questionnaire D'Alimentation. Rev CEFAC. 2016. In press.

15. Muller K, Morais J, Feine J. Nutritional and anthropometric analysis of edentulous patients wearing implant overdentures or conventional dentures. Braz Dent J. 2008;19(2):145-50. http://dx.doi.org/10.1590/ S0103-64402008000200011. PMid:18568230.

16. Peres KG, Latorre MRDO, Peres MA, Traebert J, Panizzi M. Impact of dental caries and dental fluorosis on 12-year-old schoolchildren's self-perception of appearance and chewing. Cad Saúde Publica. 2003;19(1):323-30. http:// dx.doi.org/10.1590/S0102-311X2003000100037. PMid:12700814.

17. Hassan AH, Amin HE-S. Association of orthodontic treatment needs and oral health-related quality of life in young adults. Am J Orthod Dentofacial Orthop. 2010;137(1):42-7. http://dx.doi.org/10.1016/j.ajodo.2008.02.024. PMid:20122429.

18. Uçüncü N, Ertugay E. The use of the index of orthodontic treatment need (IOTN) in a school population and referred population. J Orthod. 2001;28(1):45-52. http://dx.doi.org/10.1093/ortho/28.1.45. PMid:11254803.
19. Aaronson N, Alonso J, Burnam A, Lohr KN, Patrick DL, Perrin E, et al Assessing health status and quality-of-life instruments: attributes and review criteria. Qual Life Res. 2002;11(3):193-205. http://dx.doi. org/10.1023/A:1015291021312. PMid:12074258.

20. Leão AT, Oliveira BH. Questionários na pesquisa odontológica. In: Luiz RR, Costa AJL, Nadanovsky P. Epidemiologia e bioestatística na pesquisa odontológica. São Paulo: Atheneu; 2005. p. 273-90.

21. Hatch JP, Shinkai RS, Sakai S, Rugh JD, Paunovich ED. Determinants of masticatory performance in dentate adults. Arch Oral Biol. 2001;46(7):6418. http://dx.doi.org/10.1016/S0003-9969(01)00023-1. PMid:11369319.

22. Decerle N, Nicolas E, Hennequin M. Chewing deficiencies in adults with multiple untreated carious lesions. Caries Res. 2013;47(4):330-7. http:// dx.doi.org/10.1159/000348397. PMid:23486224.

23. Friedlander AH, Weinreb J, Friedlander I, Yagiela JA. Metabolic syndrome: pathogenesis, medical care and dental implications. J Am Dent Assoc. 2007;138(2):179-87. http://dx.doi.org/10.14219/jada.archive.2007.0134. PMid: 17272372

24. Rios-Vera V, Sánchez-Ayala A, Senna PM, Watanabe-Kanno G, Cury AA, Garcia RC. Relationship among malocclusion, number of occlusal pairs and mastication. Braz Oral Res. 2010;24(4):419-24. http://dx.doi.org/10.1590/ S1806-83242010000400008. PMid:21180962.

25. O'Brien K, Wright JL, Conboy F, Macfarlane T, Mandall N. The child perception questionnaire is valid for malocclusions in the United Kingdom. Am J Orthod Dentofacial Orthop. 2006;129(4):536-40. http://dx.doi org/10.1016/j.ajodo.2004.10.014. PMid:16627180.

26. O'Brien C, Benson PE, Marshman Z. Evaluation of a quality of life measure for children with malocclusion. J Orthod. 2007;34(3):185-93. http://dx.doi. org/10.1179/146531207225022185. PMid:17761802.

27. Kimoto K, Takahiro O, Garrett NR, Toyoda M. Assessment of masticatory performance - methodologies and their application. Prosthodont Res Pract. 2004;3(1):33-45. http://dx.doi.org/10.2186/prp.3.33.

28. Prado MMS, Borges TF, Prado CJ, Gomes VL, Neves FD. Masticatory function of subjects rehabilitated with conventional complete denture. Pesq Bras Odontoped Clin Integr. 2006;6(3):259-66.

29. Östberg AL, Bengtsson C, Lissner L, Hakeberg M. Oral health and obesity indicators. BMC Oral Health. 2012; 12(50):1-7.

30. Rosanova GCL, Gabriel BS, Camarini PMF, Gianini PES, Coelho DM, Oliveira AS. Validade concorrente da versão Brasileira do SRS-22r com o Br-SF-36. Braz J Phys Ther. 2010;14(2):121-6. http://dx.doi.org/10.1590/ S1413-35552010005000012.

\section{Author contributions}

MHM was the study's main author. TSB and CF made critical comments on the study design and on the manuscript. PMC was the head of the present research and acted as a supervisor. MHM and PMC wrote the manuscript. All authors have read and approved the final manuscript. 